\title{
PENGGUNAAN OBAT SEJAK DINI (TANYA LIMA O) KEPADA SISWA/I SMA NEGERI 1 SUKAMARA
}

\author{
Brilliyanti Monica $^{1}$ Febriyan Mulyanto ${ }^{2}$ Aulia Rahmi ${ }^{3}$ \\ ${ }^{123}$ STIKes Borneo Cendekia Medika Pangkalan Bun \\ ${ }^{1}$ Email : brillyantimonica@yahoo.co.id
}

\begin{abstract}
ABSTRAK
Pengetahuan masyarakat mengenai dunia kesehatan, terutama obat masih sangat terbatas, padahal obat merupakan bahan yang mudah kita temukan di sekitar kita. Obat berperan sangat penting dalam pelayanan kesehatan. Penanganan dan pencegahan berbagai penyakit tidak dapat dijelaskan dari tindakan terapi dengan obat atau farmakoterapi. Berbagai pilihan obat saat ini tersedia, sehingga diperlukan pertimbangan-pertimbangan yang cermat dalam memilih obat untuk suatu penyakit. Obat harus selalu digunakan secara benar agar memberikan manfaat klinik yang optimal. Metode yang kami gunakan dalam penyuluhan ini adalah dengan metode demonstrasi dan tanya jawab yang berkaitan tentang pengenalan logo-logo obat, tentang Tanya Lima $\mathrm{O}$ (apa nama dan kandungannya, apa indikasinya, berapa dosisnya, bagaimana cara menggunakannya, dan apa efek sampingnya) kepada siswa/i SMA Negeri 1 Sukamara.Dari kegiatan ini diketahui bahwa siswa/i SMA Negeri 1 Sukamara ternyata masih belum memahami tentang penggunaan obat sejak dini (Tanya Lima O). Hampir seluruh siswa/i belum mengerti dan paham tentang penggunaan obat sejak dini (Tanya Lima O). Dengan adanya kegiatan penyuluhan pengabdian masyarakat ini seharusnya masyarakat dapat lebih dini mengenal tentang obat dan bagaimana cara penggunana yang baik dan benar sehingga tidak menimbulkan resiko yang tidak diinginkan dan penyalahgunaan obat menjadi berkurang.
\end{abstract}

Kata kunci : masyarakat, obat

\section{EARLY USE OF THE DRUG (TANYA LIMA O) TO STUDENTS/I SMA NEGERI 1 SUKAMARA}

\begin{abstract}
Public knowledge about the health world, especially the drug is still very limited, whereas medicine is an easy ingredient we find around us. The drug plays a very important role in health care. The handling and prevention of various diseases can not be explained from the therapeutic action with drugs or pharmacotherapy. A wide selection of medications is currently available, so it takes careful consideration in choosing a cure for a disease. The drug should always be used properly in order to provide optimal clinical benefits. The method we use in this counseling is by demonstration methods and related questions about the introduction of the drug logos, about Tanya Lima $O$ (what is its name and content, what is the indication, how much dose, how to use it, and what side effects) to students/I SMA Negeri 1 Sukamara. From this activity it is known that students/I SMA Negeri 1 Sukamara is
\end{abstract}


still not understand about the use of the drug since early (Tanya Lima O). Almost all students have not understood and understand the use of the drug early (Tanya Lima $O$ ). With the outreach activities this community should be able to know more about the drug and how to use good and correct so as not to pose unwanted risks and drug abuse is reduced.

Keywords: society, medicine

\section{Pendahuluan}

Pengetahuan masyarakat mengenai dunia kesehatan, terutama obat masih sangat terbatas, padahal obat merupakan bahan yang mudah kita temukan di sekitar kita. Obat berperan sangat penting dalam pelayanan kesehatan. Penanganan dan pencegahan berbagai penyakit tidak dapat dijelaskan dari tindakan terapi dengan obat atau farmakoterapi. Berbagai pilihan obat saat ini tersedia, sehingga diperlukan pertimbanganpertimbangan yang cermat dalam memilih obat untuk suatu penyakit. Obat harus selalu digunakan secara benar agar memberikan manfaat klinik yang optimal. (Anidya et al., 2005).

Kegiatan pembelajaran di SMA mengutamakan belajar sambil berdiskusi. Secara alamiah bermain memotivasi anak untuk mengetahui sesuatu lebih mendalam, dan secara spontan anak mengembangkan kemampuannya (Bredecamp, 1997).

Pendidikan Sekolah Menengah Atas (SMA) merupakan jenjang pendidikan menengah pada pendidikan formal di Indonesia setelah lulus Sekolah Menengah Pertama. Sekolah Menengah Atas ditempuh dalam waktu tiga tahun, mulai dari kelas 10 sampai kelas 12. Pelajar SMA umumnya berusia 16-18 tahun. SMA diselenggarakan oleh pemerintah maupun swasta (Wikipedia, 2018). Cara meningkatkan kualitas penduduk salah satunya yaitu melalui peningkatkan kesehatan yang diawali dengan peningkatan pengetahuan secara dini mengenai pentingnya kesehatan.

"Tanya Lima O" merupakan 5 (lima) pertanyaan minimal yang harus terjawab sebelum seseorang mengonsumsi obat merujuk pada kata "obat", yaitu: obat ini apa nama dan kandungannya, obat ini apa khasiat/indikasinya, obat ini berapa dosisnya, obat ini bagaimana cara menggunakannya, dan obat ini apa efek sampingnya. (Erie Gusnellyanti,2017).

Selain lima pertanyaan pada Tanya Lima O ini, masyarakat diharapkan dapat bertanya hal lain yang diperlukan terkait dengan obat yang akan dan sedang dikonsumsi. Pada obat bebas yang dapat diperoleh tanpa resep dokter, semua informasi tersebut tercantum dengan jelas pada kemasan obat. Sedangkan pada obat keras yang diperoleh dengan resep dokter, masyarakat dapat bertanya pada dokter yang meresepkan atau pada apoteker pada saat menebus resep. Dalam GeMa CerMat, keterlibatan masyarakat secara aktif sangatlah diharapkan (Erie Gusnellyanti,2017).

\section{METODE PENELITIAN}

Metode yang kami gunakan dalam penyuluhan ini adalah dengan metode 
demonstrasi dan tanya jawab yang berkaitan tentang pengenalan logologo obat, tentang Tanya Lima O (apa nama dan kandungannya, apa indikasinya, berapa dosisnya, bagaimana cara menggunakannya, dan apa efek sampingnya) kepada siswa/i SMA Negeri 1 Sukamara.

\section{HASIL DAN PEMBAHASAN}

Kegiatan ini berupa penyuluhan mengenai penggunaan obat sejak dini dengan metode demonstrasi dan tanya jawab. Penyuluhan dilaksanakan di SMA Negeri 1 Sukamara. Tujuan kegiatan ini adalah untuk meningkatkan pengetahuan siswa/i sekolah dasar khususnya kelas 5 mengenai obat dengan metode demontrasi dan tanya jawab sehingga akan meningkatkan pengetahuan siswa/i dalam penggunaan obat. SMA Negeri 1 Sukamara terletak di JL. Iskandar, Desa/Kelurahan Mendawai Kabupaten Sukamara dengan kondisi lingkungan sekitar yang banyak terdapat kantor pemerintah disekitarnya. Jumlah kelas di SMA Negeri 1 Sukamara ada 10 kelas masing-masing berisi sekitar 30 siswa/i. Penyuluhan di SMA Negeri 1 Sukamara akan diberikan pada siswa/i kelas X.

Materi yang diberikan dalam penyuluhan ini langsung disampaikan kepada siswa/i SMA Negeri 1 Sukamara oleh mahasiswa/i Pengmas. Materi yang disampaikan mengenai pengenalan logo-logo obat, tentang Tanya Lima $O$ (apa nama dan kandungannya, apa indikasinya, berapa dosisnya, bagaimana cara menggunakannya, dan apa efek sampingnya) dengan metode demonstrasi dan tanya jawab serta mengajak bernyanyi bersama siswa/i
SMA Negeri 1 Sukamara tentang lagu "Tanya Lima O".

Dari kegiatan ini diketahui bahwa siswa/i SMA Negeri 1 Sukamara ternyata masih belum memahami tentang penggunaan obat sejak dini (Tanya Lima O). Hampir seluruh siswa/i belum mengerti dan paham tentang penggunaan obat sejak dini (Tanya Lima O) dengan metode demontrasi dan tanya jawab. Setelah kegiatan ini terlaksana, siswa/i menjadi mengerti dan paham tentang apa itu Tanya Lima $\mathrm{O}$ dengan metode demonstrasi dan tanya jawab. Hal itu ditandai dengan siswa/i mampu menjawab pertanyaan tentang penggunaan obat sejak dini (Tanya Lima O) dengan metode tanya jawab dan bagi siswa/i yang bisa menjawab pertanyaan mendapatkan hadiah. Kegiatan ini juga mendapatkan sambutan yang positif dari pihak guru dan kepala sekolah serta diikuti dengan sangat antusias oleh seluruh siswa. Kegiatan ini diharapkan dapat meningkatkan citra positif profesi apoteker di masyarakat sehingga tercipta suasana lingkungan yang menyehatkan bagi semua orang.

\section{KESIMPULAN DAN SARAN}

\section{Kesimpulan}

Setelah kegiatan program pengabdian kepada masyarakat pada siswa/i SMA Negeri 1 Sukamara ini terlaksana, siswa/i menjadi mengerti dan paham tentang penggunaan obat sejak dini (Tanya Lima O) dengan metode demonstrasi dan tanya jawab.

Penting untuk disadari bahwa obat merupakan substansi yang tidak hanya dapat memberikan manfaat, tetapi juga bahaya. Obat hanya akan memberikan manfaat jika digunakan dalam cara 
pakai yang benar dan jika dengan benar pula. Dengan pengetahuan yang benar, masyarakat akan dapat memperoleh manfaat maksimal dari obat dan dapat meminimalkan segala hal yang tidak diinginkan yang dapat terjadi akibat pemakaian suatu obat. Kegiatan ini mendapatkan sambutan yang positif dari pihak guru dan kepala sekolah serta diikuti dengan sangat antusias oleh seluruh siswa. Kegiatan ini diharapkan dapat meningkatkan citra positif profesi apoteker di masyarakat sehingga tercipta suasana lingkungan yang menyehatkan bagi semua orang.

\section{Saran}

Dengan adanya kegiatan penyuluhan pengabdian masyarakat ini seharusnya masyarakat dapat lebih dini mengenal tentang obat dan bagaimana cara penggunana yang baik dan benar sehingga tidak menimbulkan resiko yang tidak diinginkan dan penyalahgunaan obat menjadi berkurang.

\section{DAFTAR PUSTAKA}

Holidah, D., dkk., Program Iptek Bagi Masyarakat Apoteker Kecil., Universitas Jember., hal 1-9.

BAB 1 PENDAHULUAN., 2016., http://scholar.unand.ac.id/104 85/7/BAB\%20I.pdf diakses pada tanggal 11 Desember 2018 pukul 17.36 WIB

BPOM. (2008). Pengetahuan Tentang Obat: Perlunya Pendekatan dari Perspektif Masyarakat.,Majalah Info POM Vol. 9 No. 4

Cahyani, T., dkk., 2018., Peningkatan Pengetahuan Tentang Obat
Melalui Kegiatan Apoteker

Kecil Untuk Siswa Sekolah

Dasar Di Desa Selogiri

Kecamatan Karanggayam

Kabupaten Kebumen., The

7th University Research

Colloqium STIKES PKU

Muhammadiyah Surakarta., hal 182.

Lentera,K.,2011.,Pengertian

Sekolah.,https://lenterakecil.c om/pengertian-

sekolah/diakses pada tanggal

17 Desember 2018 pukul 15.34 WIB 